\title{
Long-term follow-up of curcumin treated MGUS/SMM patients - an updated single centre experience
}

\author{
Terry Golombick $^{1 *}$, Terrence H. Diamond ${ }^{1}$, Arumugam Manoharan ${ }^{2}$ and Rajeev Ramakrishna ${ }^{2}$ \\ ${ }^{1}$ Department of Endocrinology, St George Hospital, Sydney, Australia \\ ${ }^{2}$ Southern Sydney Haematology, University of Wollongong, NSW, Australia
}

Multiple myeloma (MM) evolves through a spectrum of disease from a premalignant stage of monoclonal gammopathy of undetermined significance (MGUS) (serum M-protein value of $<30$ $\mathrm{g} / \mathrm{L}$, bone marrow plasma cells $<10 \%$, no or small amount of M-protein in the urine, and absence of lytic bone lesions, anemia, hypercalcemia, or renal insufficiency) to an intermediate stage of smoldering multiple myeloma (SMM) (serum M protein level $>30 \mathrm{~g} / \mathrm{L}$ and/or bone marrow plasma cells $>10 \%$, plus no anaemia, hypercalcemia, renal failure, or lytic bone lesions) and finally presents with symptoms and signs of end-organ damage which leads to the diagnosis of MM [1]. Studies indicate that almost all cases of MM are preceded by the precursor state of MGUS or SMM [2].

Patients with MGUS or SMM are not offered therapeutic options to date and standard of care remains observation with re-evaluations of the patient every 3-4 months. Long-term monitoring of untreated MGUS/SMM patients has shown that the monoclonal protein can disappear spontaneously during follow-up only in MGUS patients with low initial concentrations of monoclonal protein $(5 \mathrm{~g} / \mathrm{L})$ [3]. There are no reports of the monoclonal protein decreasing or disappearing spontaneously in SMM patients.

Because symptomatic myeloma may not evolve for as long as 20 years, it is currently not possible to predict the clinical course of MGUS or SMM. Features predicting patients at highest risk of disease progression include the size and type of M-protein, with IgA having a higher risk compared to IgG paraprotein, \% plasma cell dyscrasia, and abnormal serum-free light chain ratio. A number of studies have shown that independent of the size and type of the serum M-protein, an abnormal free lightchain (FLC) ratio increases the risk of progression [4].

Given the uncertainty of disease progression with MGUS and SMM, early intervention aimed at potentially slowing down or stopping disease progression might be therapeutic. Curcuma longa (turmeric) is a tropical plant native to southern and southeastern tropical Asia. It is a perennial herb belonging to the ginger family. The most active component in turmeric is curcumin [5]. Curcumin has been shown to inhibit the proliferation of multiple myeloma cells through the downregulation of IL- 6 and NF-kB. Bharti et al. showed that curcumin suppresses proliferation and induces apoptosis in multiple myeloma cells through the suppression of RANKL signaling [6].

Based on its antimyeloma cell activity, we have performed a number of studies with curcumin in MGUS/SMM patients, including a randomised, double-blind placebo- controlled cross-over study, published in the American Journal of Hematology [7] where we showed that treatment of MGUS/SMM patients with curcumin resulted in an improvement in markers of disease progression (i.e., free light-chain ratio (rFLC), paraprotein levels, percentage plasma cells) in some patients [8]. A number of patients who participated in our studies and who showed a benefit, have continued to take curcumin over a number of years, of their own volition, even though the studies in which they were participating are complete.

We present here an update on the long-term follow-up of 13 MGUS/SMM patients who have been taking curcumin (at a dose of 4-8 grams daily) for a period of 3-9 years (Table 1). The patients are monitored every 3-6 months with blood tests being done at each monitoring visit. As far as we know, we are the only centre treating MGUS/SMM patients with curcumin.

From the table, it can be seen that there are 6 MGUS and 7 SMM patients, 11 are IgG, 1x IgA and 1x IgM. Eight have kappa disease and 5 have lambda disease. Six patients are male and 7 females and the average age is 68 years. The median time of curcumin administration is 5.6 years and only one patient has developed progressive disease (patient no. 8 - cardiac amyloidosis) after 6 years of curcumin therapy. This patient has commenced anti-myeloma therapy. Five patients showed a decrease in paraprotein levels, 3 increased slightly while the rest remained stable. The bone marrow plasma cells decreased in 4 patients and increased modestly in 2 others while it remained the same in 3. Three MGUS patients have not had bone marrow aspirates/ biopsies done. Five patients showed a decrease in hemoglobin while it increased slightly or remained stable in the others. Whilst the involved free light chain increased in most patients, this was accompanied by an increase in the uninvolved free light chain in most of the patients, leading to a decrease in ratio in 3 of the patients.

There is currently much debate about early treatment of high risk SMM patients, with updated IMWG diagnostic criteria for early treatment. These include serum free-light chains ratio $>100,>60 \%$ plasma cells and $>1$ focal lesion by MRI. Several trials have been initiated to test early intervention in high-risk SMM patients. While some of the trials have shown benefit to high risk SMM patients, most of these trials have been associated with toxic events which has included hematologic events (neutropenia, thrombocytopenia, anemia) and nonhematologic events (infection, rash, asthenia, constipation, diarrhoea, deep-vein thrombosis).

Correspondence to: Terry Golombick, Department of Endocrinology, St George Hospital, Sydney, Australia, Tel: 029113 2767; Mobile: 0414939655; Fax: 029113 3966; E-mail: terry.golombick@health.nsw.gov.au

Received: April 20, 2017; Accepted: April 27, 2017; Published: April 29, 2017 
Table 1. MGUS/SMM patient responses after years of curcumin therapy.Pt no: patient number; M: male; F: female; curc yrs: curcumin years; Hb: haemoglobin; Pp: paraprotein; Bsl: baseline (at start of curcumin therapy); Eos: end of study period; iflc: involved free light chain; uiflc: uninvolved free light chain; rflc: free light chain ratio; \% pc: percentage plasma cells; tp: total protein.

\begin{tabular}{|c|c|c|c|c|c|c|c|c|c|c|c|c|c|c|c|c|c|c|}
\hline Pt no. & sex & age & $\mathbf{P p}$ & $\begin{array}{c}\text { Curc } \\
\text { yrs }\end{array}$ & $\begin{array}{c}\text { Bsl } \\
\text { Hb } \\
(119-160 \mathrm{~g} / \mathrm{L})\end{array}$ & $\begin{array}{c}\text { Eos Hb } \\
(119- \\
160 \mathrm{~g} / \mathrm{L})\end{array}$ & $\begin{array}{c}\text { Bsl pp } \\
(\mathrm{g} / \mathrm{L})\end{array}$ & $\begin{array}{c}\text { Eos pp } \\
(\mathrm{g} / \mathrm{L})\end{array}$ & $\begin{array}{l}\text { Bsl iflc } \\
(\mathrm{mg} / \mathrm{L})\end{array}$ & $\begin{array}{l}\text { Eos iflc } \\
(\mathrm{mg} / \mathrm{L})\end{array}$ & $\begin{array}{c}\text { Bsl uiflc } \\
(\mathrm{mg} / \mathrm{L})\end{array}$ & $\begin{array}{c}\text { Eos uiflc } \\
(\mathrm{mg} / \mathrm{L})\end{array}$ & $\begin{array}{c}\text { Bsl rflc } \\
(0.3-1.7)\end{array}$ & $\begin{array}{c}\text { Eos rflc } \\
(0.3-1.7)\end{array}$ & $\begin{array}{c}\text { Bsl } \\
\% \text { pc }\end{array}$ & $\begin{array}{l}\text { Eos } \\
\% \text { pc }\end{array}$ & $\begin{array}{c}\text { Bsl tp } \\
(64- \\
83 g / L)\end{array}$ & $\begin{array}{c}\text { Eos tp } \\
(64- \\
83 \mathrm{~g} / \mathrm{L})\end{array}$ \\
\hline 1 & $\mathrm{M}$ & 71 & IgGk & 9 & 133 & 136 & 26 & 13.6 & 225 & 226 & 9.59 & 12.4 & 23.46 & 18.2 & 5 & 5 & 91 & 85 \\
\hline 2 & $\mathrm{M}$ & 55 & IgGk & 7 & 109 & 111 & 28.5 & 16.1 & 97.7 & 1090 & 3.65 & 236 & 26.77 & 4.6 & 33 & 29 & 91 & 73 \\
\hline 3 & $\mathrm{M}$ & 73 & IgGk & 5 & 128 & 134 & 32 & 37 & 29 & 31 & 19 & 11 & 1.53 & 2.82 & 44 & 25 & 91 & 94 \\
\hline 4 & $\mathrm{M}$ & 74 & IgGL & 9 & 136 & 110 & 27 & 24.7 & 53.2 & 98.8 & 15.7 & 50.7 & 0.3 & 0.5 & 7 & 18 & 87 & 86 \\
\hline 5 & $\mathrm{M}$ & 74 & IgGL & 3 & 141 & 111 & 28 & 28 & 64 & 83 & 6 & 10 & 0.09 & 0.12 & 20 & 11 & 95 & 86 \\
\hline 6 & $\mathrm{~F}$ & 89 & IgAk & 3 & 135 & 106 & 11.6 & 12 & 417 & 551 & 10.9 & 5.3 & 38.3 & 104 & 15 & 15 & 71 & 65 \\
\hline 7 & $\mathrm{M}$ & 50 & IgGL & 6 & 144 & 139 & 29 & 34.6 & 15 & 41.3 & 6.8 & 8.95 & 0.45 & 0.2 & 10 & 10 & 101 & 101 \\
\hline 8 & F & 77 & IgGk & 6 & 117 & 102 & 24.5 & 20.8 & 132 & 455 & 6.02 & 8.3 & 21.93 & 54.8 & 6 & 19 & 91 & 81 \\
\hline 9 & $\mathrm{~F}$ & 63 & IgGk & 5 & 122 & 128 & 25 & 19.8 & 54.1 & 114 & 5.82 & 7.2 & 9.3 & 15.8 & 16 & 15 & 86 & 83 \\
\hline 10 & $\mathrm{~F}$ & 51 & IgGk & 3 & 132 & 132 & 10 & 10 & 29 & 33 & 20 & 17 & 1.88 & 1.94 & & & 74 & 73 \\
\hline 11 & $\mathrm{~F}$ & 64 & IgGL & 3 & 134 & 130 & 11.5 & 11.4 & 10.2 & 9.1 & 1.9 & 6.3 & 0.2 & 0.7 & & & 80 & 72 \\
\hline 12 & $\mathrm{~F}$ & 66 & IgMk & 3 & 138 & 141 & 12 & 15.3 & 577 & 704 & 2 & 2.8 & 288.5 & 251.4 & & & 73 & 78 \\
\hline 13 & $\mathrm{~F}$ & 73 & IgGL & 3 & 131 & 112 & 17 & 17 & 61 & 93 & 4 & 7 & 0.07 & 0.08 & 7 & 8 & 79 & 76 \\
\hline
\end{tabular}

Our data suggest that curcumin administration may benefit some patients diagnosed with MGUS or SMM with little or no toxicity even after 9 years of therapy. Future studies should assess the role of curcumin in both MGUS and SMM patients - prior to progression to high risk or active myeloma - as this may lead to a delay in or may even stop disease progression. Although one patient has progressed to amyloidosis, the other twelve have maintained stable disease with no clear evidence of disease progression. Patient tolerance has been good and none have developed clinical infections. The drawback of this correspondence is the small number of patients on long-term curcumin therapy.

\section{Acknowledgments}

Thanks to Caila Rothwell for assistance with data collection.

There is no conflict of interest to declare.

\section{References}

1. Kyle RA, Durie BG, Rajkumar SV, Landgren O, Blade J, et al. (2010) Monoclonal gammopathy of undetermined significance(MGUS) and smoldering (asymptomatic) multiple myeloma: IMWG consensus perspectives risk factors for progression and guidelines for monitoring and management. Leukemia 24: 1121-1127.

2. Landgren O, Kyle RA, Pfeiffer RM, Katzmann JA, Caporaso NE, et al. Monoclonal gammopathy of undetermined significance (MGUS) consistently precedes multiple myeloma: a prospective study. Blood 113: 5412-5417.

3. Kyle RA, Therneau TM, Rajkumar SV, Offord JR, Larson DR, et al. (2002) A longterm study of prognosis in monoclonal gammopathy of undetermined significance. $N$ Engl J Med 346: 564-569. [Crossref]

4. Dispenzieri A, Kyle RA, Katzmann JA, Therneau TM, Larson D, et al. (2008) Immunoglobulin free light chain ratio is an independent risk factor for progression of smoldering (asymptomatic) multiple myeloma. Blood 111: 785-789. [Crossref]

5. Aggarwal BB, Kumar A, Aggarwal MS, Shisodia S (2005) Curcumin derived from turmeric curcuma longa: A spice for all seasons. Phytopharm Cancer Chemoprev pp: 349-387.

6. Bharti AC, Donato N, Singh S, Aggarwal BB (2003) Curcumin (diferuloylmethane) down-regulates the constitutive activation of nuclear factor-kappa B and IkappaBalpha kinase in human multiple myeloma cells, leading to suppression of proliferation and induction of apoptosis. Blood 101: 1053-1062. [Crossref]

7. Golombick T, Diamond TH, Manoharan A, Ramakrishna R (2012) Monoclonal gammopathy of undetermined significance, smoldering multiple myeloma, and curcumin: a randomized, double-blind placebo-controlled cross-over $4 \mathrm{~g}$ study and an open-label 8g extension study. Am J Hematol 87: 455-460. [Crossref]

8. Golombick T, Diamond T, Manoharan A, Ramakrishna R (2013) Long term use of curcumin in two smoldering multiple myeloma patients. J Hematological Malignancies 3: $18-23$.

Copyright: (C2017 Golombick T. This is an open-access article distributed under the terms of the Creative Commons Attribution License, which permits unrestricted use, distribution, and reproduction in any medium, provided the original author and source are credited. 